14 Ramsay HM, Goddard W, Gill S, et al. Herbal creams used for atopic eczema in Birmingham UK illegally contain potent corticosteroids. Arch Dis Child 2003:88:1056-7.

15 Geiling EMK, Cannon PR. Pathological effects of elixir of sulphanilamide (diethylene glycol) poisoning. JAMA 1938;111:919-26.
16 Okuonghae HO, Ighogboja IS, Lawson JO, et al. Diethylene glycol poisoning in Nigerian children. Ann Trop Paediatr 1992;12:235-8.

17 Hanif M, Mobarak MR, Ronana A, et al. Fatal renal failure caused by diethylene glycol in paracetamol elixir: the Bangladesh epidemic BMJ 1995;311:88-91.

\title{
Detection of leptospirosis in India
}

\section{$J$ M Vinetz}

\section{A commentary on the paper by Karande et al}

eptospirosis is a zoonotic disease of global significance. ${ }^{1}$ In recent years, -clinicians and epidemiologists have given increasing attention to this disease, with particular focus on two features: its epidemic potential; and severe manifestations, particularly pulmonary haemorrhage. ${ }^{23}$ However, in leptospirosis endemic regions, one quarter of patients (or more) presenting with simple fever have serological results suggesting the diagnosis of acute leptospirosis. Severe leptospirosis seems to be the tip of the iceberg of leptospiralinfection: most peopleinfected by Leptospira seem to have either have simple, undifferentiated fever (fever without focus) or subclinical illness. ${ }^{4}$

Fever is a cardinal manifestation of illness and is a common clinical complaint. In industrialised countries, an undifferentiated febrile illness is often referred to a "viral syndrome" or a "flulike illness", with the expectation that it will resolve itself. In the developing world, depending on locale, an undifferentiated fever may be called "dengue" or "malaria", or depending on the verve of the investigator, a "rickettsial" or "ehrlichial" illness, etc. Regardless of geographic context, however, most often the diagnosis of an undifferentiated fever is on the basis of clinical observation without precise documentation by laboratory, and treatment is symptomatic or specific antimicrobial therapy provided empirically. I would suggest that the term "flu-like illness" is a misnomer and should simply be abandoned as dangerous and the result of fuzzy thinking.

What really is meant by "flu-like illness"? To this author, an influenzalike illness is characterised by the onset of general symptoms such as fever, headache, myalgia, arthralgia, accompanied by upper or lower respiratory symptoms such as sore throat, nasal congestion, and cough. While influenza has a prodrome indistinguishable from many other acute infections, its archetypal manifestations are respiratory. Therefore, regardless of geographic location, to describe fever accompanied by general complaints, without respiratory symptoms, as "flulike" or "viral syndrome" is fraught with hazard and should prompt consideration of other diagnostic possibilities. The underlying meaning of "flu-like illness" is profoundly important, however, particularly today in the era of bioterrorism (for example, pulmonary anthrax which starts out as an undifferentiated fever, later progressing to pulmonary manifestations) and the severe acute respiratory syndrome (SARS). One can only judge with apprehension the next influenza season when many true "flulike" syndromes present to hospital!

\section{"An outbreak of febrile illness occurred in the context of seasonal flooding in Mumbai"}

So it was the diagnostic importance of undifferentiated fever that motivated Karande et al to study leptospirosis in Mumbai, as reported in this issue of the Archives. ${ }^{5}$ The authors took advantage of an outbreak of febrile illness that occurred in the context of seasonal flooding in Mumbai. As is typical with outbreaks of undifferentiated fever, ${ }^{2}{ }^{6}$ public health authorities thought that the outbreak was a "viral" or "dengue-like" illness. When diagnostic testing showed no evidence of dengue virus transmission, other diagnostic possibilities were considered; among them, for some reason not described by the authors, leptospirosis. During a six week period following the Mumbai flood of July 2000, public health authorities in Mumbai issued a directive to admit all patients reporting to its public hospitals with undifferentiated fever and study them for leptospirosis. The paediatrics department at the authors' institution admitted 53 children aged 1 month to 12 years of age with suspected leptospirosis. About one third had serological results suggesting acute leptospirosis. Of equal importance, there were a number of other final diagnoses in these patients, including malaria and
18 O'Brien KL, Selanikio JD, Hecdivert C, et al. Epidemic of paediatric deaths from acute renal failure caused by diethylene glycol poisoning. JAMA 1998;379:1175-80.

typhoid. The risk of leptospirosis rose with age; most cases were 6-12 years old. Four clinical features seemed to be helpful in distinguishing leptospirosis from other causes of fever: contact with flood water, conjunctival suffusion (conjunctival erythema without discharge), abdominal pain, and rash (maculopapular and erythematous, most prominent on the trunk). The zoonotic origin of infection was not investigated. There were no fatalities; all confirmed leptospirosis cases received intravenous penicillin and recovered without sequelae.

The paper of Karande et al is nominally about leptospirosis but raises a central issue in emerging infectious diseases regarding the importance of undifferentiated fever occurring in an epidemic setting. The authors make specific recommendations about the importance of working up patients who come into contact with flood waters, and that children ought to avoid playing in and walking through flood waters. More important for public health, there needs to be a general awareness and deeper understanding of the concept of undifferentiated febrile illness. Astute clinicians and well equipped clinical laboratories need to be vigilant in observing and explaining outbreaks of undifferentiated febrile illness. Only in this way can we avoid the intellectual abyss of dismissing such clinical presentations as only "viral" or "flu-like" illnesses, and delay the recognition of important epidemics of known and newly emerging infectious diseases.

\section{Arch Dis Child 2003:88:1033}

Correspondence to: Associate Professor J M Vinetz, Division of Infectious Diseases, Department of Medicine, University of California, San Diego School of Medicine, 9500 Gilman Drive, Mail Code 0640, La Jolla, CA 92039-0640, USA; jvinetz@ucsd.edu

\section{REFERENCES}

1 World Health Organization. Leptospirosis worldwide, 1999. Wkly Epidemiol Rec 1999;74(29):237-42.

2 Trevejo RT, Rigau-Perez JG, Ashford DA, et al. Epidemic leptospirosis associated with pulmonary hemorrhage-Nicaragua, 1995. J Infect Dis 1998; 178: 1457-63.

3 Ko Al, Galvao Reis M, Dourado CMR, et al. Urban epidemic of severe leptospirosis in Brazil. Lancet 1999;354:820-5.

4 Ashford DA, Kaiser RM, Spiegel RA, et al. Asymptomatic infection and risk factors for leptospirosis in Nicaragua. Am J Trop Med Hyg 2000;63:249-54.

5 Karande S, Bhatt M, Kelkar A, et al. An observational study to detect leptospirosis in Mumbai, India, 2000. Arch Dis Child 2003;88:1070-5.

6 Sanders EJ, Rigau-Perez JG, Smits HL, et al. Increase of leptospirosis in dengue-negative patients after a hurricane in Puerto Rico in 1996. Am J Trop Med Hyg 1999;61:399-404. 